\title{
Toxicology from across the pond
}

\author{
RS Hoffman \\ Associate Professor of Emergency Medicine and Medicine (Clinical Pharmacology), New York University School of Medicine, and Director, New York \\ City Poison Control Center, New York City Department of Health and Mental Hygiene, New York, USA
}

This review is based on a presentation by Professor Hoffman at the RCPE's 49th St Andrew's Day Festival on 4 December 2009.

\begin{abstract}
Despite extensive educational and preventive efforts, fatality from poisoning is a growing public health concern. While strategies to reduce fatal unintentional poisoning in children have been largely successful, growing numbers of deaths from suicidality and substance abuse present unique challenges to the public health system. This paper explores three areas where new approaches hope to mitigate major causes of poison-related fatality. Included in this discussion are bystander naloxone for opioid overdose, a reconsideration of the optimal dose of $\mathrm{N}$-acetylcysteine therapy and intravenous fat emulsion (lipid rescue) therapy for cardiovascular toxins. These innovative approaches are designed to challenge dogma and provide a stimulus for individualised clinical care.
\end{abstract}

Correspondence to RS Hoffman, 455 First Avenue, Room 123, New York, NY 10016, USA

tel. +l $2 / 24478153$

e-mail bobhoffmd@gmail.com

KEYWORDS Harm reduction, intravenous fat emulsion, $\mathrm{N}$-acetylcysteine, naloxone, paracetamol, poisoning

\section{DECLARATION OF INTERESTS None declared.}

Throughout the world, the practice of toxicology is influenced by an interaction between two major forces. On one side of the equation, the epidemiology of poisoning is driven by environmental issues (natural flora and fauna), variability of toxins (urban vs agricultural region), scope of pharmaceuticals (industrialised vs developing nations) and a variety of other factors, including awareness, cultural practices and patterns of substance use or misuse. These factors interact to determine the incidence and severity of poisoning. On the other side of the equation, the response to poisoning is determined largely by the level of community and professional education and by resource availability such as number, type and distribution of hospitals, critical care beds, antidotes and ventilators.

Although estimates of the global burden of acute poisoning are astounding, the major contributors to lethality come from pesticides and venomous bites. ${ }^{1,2}$ While these events are of great concern, they are less applicable to urban areas of developed nations where pharmaceuticals, drugs of abuse and environmental toxins (such as carbon monoxide) predominate. Early attempts to reduce the consequences of poisoning in the US involved legislative solutions that mandated warning labels, minimised the concentration of caustics in household products, and required restrictive packaging materials such as child-resistant closures on high-risk toxins. ${ }^{3-6}$ Many interventions in the UK mirrored those described in America. ${ }^{7}$ Collectively, these efforts are credited with a reduction in both hospital admissions and serious and fatal childhood poisonings. A comprehensive review analysed poisoning deaths certified in children under the age of 10 years in England and Wales between 1968 and 2000. The authors noted an $80 \%$ decline in deaths, which they attributed to a variety of interventions, most notably child-resistant closures, community education and the withdrawal of harmful products. ${ }^{8}$ Unfortunately, since 2000, opioids have resurfaced as the leading cause of death.

More recent programmes have targeted intentional overdoses. One such example in the UK was an administrative control that limited the amount of paracetamol that could be dispensed at one time. Unfortunately, it is unclear if this effort has been successful.9.10 Despite these and other programmes, current data suggest that the overall mortality from poisoning is increasing. A 1998 study that evaluated injury deaths in the US between 1985 and 1995 reported that poisoning ranked third among all causes of injuryrelated mortality, only behind motor vehicle crashes and firearms fatalities." When similar data were analysed for the five years between 1999 and 2004, poisoning mortality had risen above firearms fatalities, becoming the second leading cause of unintentional injury mortality in America. ${ }^{12}$ While completed suicides from firearms fell by nearly $11 \%$, suicidal poison deaths actually increased. Likewise, despite the fall in childhood poisoning in England and Wales described above, the shift towards opioids as the leading cause of childhood fatalities is likely reflective of the increase in opioid deaths recently reported in English and Welsh men. ${ }^{13}$ Data over the same period for Scotland were strikingly similar, demonstrating a decrease in paracetamol poisoning and an increase in antidepressant and opioid poisoning. ${ }^{14}$

This paper will focus on three emerging trends designed to limit poison-related fatalities and which are most 
useful in developed urban settings. Successful interventions in developing nations, such as preventing the sale of highly toxic pesticides, will not be discussed further. ${ }^{15}$

\section{LIMITING OPIOID DEATHS}

Harm reduction for opioid addiction and toxicity began in the late 1960s in New York when Dole and Nyswander pioneered the use of methadone. ${ }^{16}$ The UK parallel involved the distribution of pharmaceutical-grade heroin designed to improve safety through the regulation of purity and dose and to limit criminal behaviours associated with drug sale and acquisition. Later, needle exchange programmes were introduced in an attempt to limit the spread of hepatitis and human immunodeficiency virus. ${ }^{17,18}$

Unfortunately, opioid deaths continued. Between 1990 and $1998,7,451$ total overdose deaths were recorded in New York City alone; I,024 were from methadone, 4,627 from heroin and 408 were attributed to both methadone and heroin. ${ }^{19} \mathrm{~A}$ follow-up study between 1990 and 2000 demonstrated a $10 \%$ increase in the percentage of overdose deaths attributed to opioids. ${ }^{20}$ By 2003 nearly $9 \%$ of all deaths certified by the New York City medical examiner tested positive for methadone. ${ }^{21}$ Comparable trends are reported from other major cities in the US, ${ }^{22,23}$ Canada $^{24}$ and the UK. ${ }^{13}$ Although it is unclear whether some of these deaths represent suicides using drugs of abuse, most authorities believe that the vast majority of fatalities result from unintended dosing errors or other complications of intentional drug use without overt suicidality. While the benefits of methadone and heroin (and, more recently, buprenorphine) therapy and needle exchange programmes are undeniable, limited enrollment, social stigma, fear of arrest and prosecution and growing trends in prescription opioid abuse maintain the rate of opioid deaths at epidemic proportions.

Although the goal of preventing overdoses has not been abandoned, recent data have forced a re-evaluation of harm-reduction strategies. Injection drug users selfreported overdose rates of $38 \%$ in the UK, $48 \%$ in the US and $59 \%$ in Russia. ${ }^{25}$ In Australia, $68 \%$ of users reported a median overdose rate of three times. ${ }^{25}$ When a group of addicts in America were followed over 22 years, $34 \%$ had died from overdose. ${ }^{26} \mathrm{~A}$ similar study from the UK showed that $52 \%$ of deaths in a cohort of addicts were from overdoses. ${ }^{27}$ These overdoses typically occurred in the presence of other people. ${ }^{28-30}$ Most commonly and somewhat intuitively, many of these 'bystanders' were also heroin users. ${ }^{31}$ In fact, nearly $90 \%$ of heroin users in Australia admitted to witnessing overdoses a median of six times. ${ }^{32}$ Unfortunately, many were reluctant to call for help for fear of arrest or prosecution.

Naloxone, a competitive opioid antagonist, has been available for the treatment of opioid overdose for decades.
Its pharmacology and uses are extensively described elsewhere. ${ }^{33}$ Notably, naloxone is highly bioavailable, not only via subcutaneous and intramuscular injection but also via nasal aerosolisation. ${ }^{34}$ The recognition that overdoses will continue to occur, often in the presence of bystanders who are familiar with drug overdose and drug administration but who are reluctant to call for help, has produced a paradigm shift towards the controlled provision of rescue naloxone to opioid users and their families.

This new direction is not free from debate. Many of the arguments against the use of bystander naloxone are the same ones previously advanced in discussions about methadone, pharmaceutical heroin and needle exchange programmes. These include concerns that many overdoses occur alone, addicts will be unable to recognise and respond to overdose, inappropriate use of naloxone may lead to complications or delay definitive care, some treated patients will be able to refuse care that is desperately needed, physicians will be reluctant to prescribe naloxone, and by making drug use safer overall use will increase. ${ }^{25,35,36}$ Although the majority of these concerns have been discussed and settled in previous eras, they continue to resurface, possibly as a result of societal pressures and rooted belief systems.

Data suggest that bystanders can be taught to recognise and respond to overdose, ${ }^{37,38}$ in much the same way bystanders can be taught to recognise and respond to choking or cardiac arrest. Moreso, numerous publications now describe successful reports of bystander administration of naloxone with high rates of survival and low rates of adverse effects. ${ }^{39-41}$ In fact, based on an analysis of the existing data a recent paper by noted authors called for an 'extensive scale-up of access to naloxone'. ${ }^{42}$

\section{LIMITING COCAINE DEATHS}

With some regional variation, cocaine use, complications and related fatalities pose as great a public health concern as opioids. ${ }^{20,43,44}$ According to the United Nations Office on Drugs and Crime's 2009 World Drug Report nearly 1,000 metric tonnes of cocaine are produced each year and largely sold in the US and Europe. Rates of use range from $1.4 \%$ in Western and Central Europe to $2.3 \%$ in North America. European prevalence rates are highest in Scotland (3.8\%) and Spain (3.0\%) and are estimated to be $2.3 \%$ in England and Wales. ${ }^{45}$

Cocaine toxicity is clinically distinct from opioid toxicity and reviewed elsewhere. ${ }^{46}$ In essence, the combined effects of central nervous system stimulation and the blockade of catecholamine reuptake interact to produce a syndrome of severe sympathomimetic excess. Patients present with hypertension, hyperthermia, tachycardia, diaphoresis, mydriasis and severe psychomotor agitation. Unfortunately, although good supportive measures such as sedation and cooling are essential interventions in 
treating patients with cocaine toxicity, there is no currently available direct antidote to cocaine.

Two areas of investigation deserve mention. Cocaine is rapidly metabolised by plasma cholinesterase (also known as butyrylcholinesterase or pseudocholinesterase). Early in-vitro work demonstrated that serum from individuals with plasma cholinesterase deficiency metabolised cocaine poorly. ${ }^{47}$ Subsequent human data associated more severe clinical cocaine toxicity with those individuals with lower plasma cholinesterase activity. ${ }^{48}$ This was later confirmed in an animal model, when induced plasma cholinesterase deficiency enhanced cocaine toxicity and the administration of exogenous plasma cholinesterase protected against lethal doses of cocaine. ${ }^{49,50}$ Current research is attempting to evaluate the use of highly efficient exogenous cocaine-esterases to protect against cocaine toxicity..$^{51}$ Although preliminary results are exciting, it is becoming obvious that methods to enhance metabolic capacity may not be clinically useful unless they can be administered within moments of a lethal dose of cocaine. This major limitation may represent a fatal flaw for attempts to translate an otherwise fascinating science into clinical utility.

Another approach to cocaine toxicity is to try to develop a vaccine against cocaine. One group has determined that humans can make anti-cocaine antibodies, and that if those antibody concentrations can be maintained, cocaine use will decrease..$^{52}$ Although this work should be considered preliminary, several obstacles have surfaced. Users have to be sufficiently motivated and compliant enough to attend frequent administrations of the vaccine. Even with complete compliance, only a minority of patients will achieve and maintain 'effective' antibody concentrations. Finally, for the minority of patients with effective antibody concentrations, success is measured as a reduction in cocaine use, not a period of cocaine abstinence. Although these obstacles may not be insurmountable, it would be premature to conclude that vaccination will be an effective strategy. For now, harm reduction efforts concentrate on education, detoxification and adjunctive pharmacological support.

\section{PARACETAMOL POISONING}

Although the case-fatality rate for paracetamol ingestion is quite low compared to cardiovascular toxins, antidepressants and pesticides, the number of paracetamol ingestions is so high that each year paracetamol poisoning is among the leading causes of drug-related fatalities reported to poison centres in the US and UK. Moreover, recent work has established that paracetamol is the leading cause of fulminant hepatic failure..$^{53,54}$

Modern treatment for paracetamol poisoning began with the seminal work of Prescott, who noted that a prolonged paracetamol elimination half-life was associated with the development of hepatic injury. ${ }^{55}$ Later, the Rumack-Matthew nomogram was developed and served as the basis for the initiation of $\mathrm{N}$-acetylcysteine (NAC) therapy, which has prevented countless cases of illness and death. ${ }^{56}$ Most of the world treated with intravenous (IV) NAC, while for years Americans used the drug orally with the rationale that higher concentrations of NAC were delivered directly to the liver via first-pass metabolism and that oral NAC administration had a lower incidence of adverse drug effects. The current standard IV regimen involves three infusions delivered over $20-21$ hours, $150 \mathrm{mg} / \mathrm{kg}$ over 15-60 minutes, $50 \mathrm{mg} / \mathrm{kg}$ over the next four hours and $100 \mathrm{mg} / \mathrm{kg}$ over the next 16 hours. In contrast, the oral regimen gives a loading dose of $140 \mathrm{mg} / \mathrm{kg}$, followed by 16 doses of $70 \mathrm{mg} / \mathrm{kg}$ every four hours. Thus the standard intravenous regimen delivers $300 \mathrm{mg} / \mathrm{kg}$, while the total dose used for the 72-hour oral regimen was I,330 mg/kg.

Since a dose-response analysis of NAC therapy was never performed, these two treatment regimens were accepted based on the recognition that they were almost uniformly protective, especially if started within approximately eight hours of paracetamol ingestion. However, at least in the US, there was generally a perception that the total dose of oral NAC therapy was excessive. This belief was supported by two lines of evidence. First, although it was well established that a significant portion of NAC was adsorbed to activated charcoal, ${ }^{57,58}$ patients with paracetamol overdoses who received both oral NAC and activated charcoal appeared to have better outcomes, even when the charcoal was given well after paracetamol absorption should have been completed. ${ }^{59,60}$ Additional evidence came from a case stratification of paracetamol-poisoned patients. When Smilkstein and colleagues compared patient outcomes based on paracetamol concentrations, no difference could be identified between groups, despite patients with substantially elevated initial paracetamol concentrations ${ }^{61}{ }^{\text {If, regardless of the dose of paracetamol }}$ ingested, NAC was equally protective, it was only logical to assume that the dose of oral NAC was excessive.

It is unclear whether this assumption can be applied to IV NAC. Recent evidence suggests that in some select cases the standard IV NAC regimen may be inadequate. Several case reports and case series have emerged where, despite having received appropriate courses of IV NAC, patients with early presentations have progressed to fulminant hepatic failure or death. ${ }^{62-64}$ These cases share common features of concern. Many either involved massive ingestions with exceedingly high initial paracetamol concentrations or the patients co-ingesting substances (such as diphenhydramine) which slowed gastrointestinal absorption or produced a second delayed peak concentration. These events have stimulated a reassessment of the current IV NAC protocol. 
At the present time it is generally accepted that NAC should be continued IV beyond the standard 20-hour (or 2l-hour) regimen for the following conditions: fulminant hepatic failure, persistence of paracetamol at the end of the NAC regimen, and possibly when there is evidence of clinical or numerical deterioration of liver function, even when paracetamol is no longer detectable in the serum. The standard practice in these situations is to continue the third maintenance infusion of NAC (6.25 mg/kg/hr or $100 \mathrm{mg} / \mathrm{kg}$ over 16 hours) until the patient improves, undergoes liver transplantation or dies. This regimen was developed at King's College Liver Institute, demonstrated to be beneficial, ${ }^{65}$ but never established to be the optimal dose.

To appreciate the concern it must be acknowledged that the antidotal effects of NAC in paracetamol overdose are complex. Early after paracetamol ingestion NAC may serve as a substrate to enhance sulfation of paracetamol to a non-toxic metabolite, and as both a glutathione precursor and a glutathione substitute to detoxify the toxic metabolite known as NAPQI. Later in the course of toxicity NAC may help to prevent oxidative damage from leukocytes and improve cardiac output and hepatic oxygen extraction. The minimal concentration of NAC required for any of these benefits has never been established.

Pharmacokinetic data demonstrate that with the standard IV infusion of NAC, plasma concentration reaches steady state at about 12 hours, which is well into the third maintenance infusion $(6.25 \mathrm{mg} / \mathrm{kg} / \mathrm{hr}){ }^{66}$ This concentration is an order of magnitude lower than concentrations achieved during the first two infusions. Since, in patients who are treated early, the half-life of paracetamol elimination is generally less than four hours (more likely I.5-2.5 hours), most patients will have low or negligible paracetamol concentrations by the time NAC concentrations have fallen to steady state. Thus it is reasonable to assume that an NAC infusion at 6.25 $\mathrm{mg} / \mathrm{kg} / \mathrm{hr}$ provides at least the minimum concentration that is efficacious for the late benefits of NAC. However, these newly described patients who appear to fail standard NAC therapy often have paracetamol concentrations at the end of NAC therapy that are far in excess of the four-hour concentrations that would have been indicative of the need to initiate therapy. These high paracetamol concentrations may require higher concentrations of NAC (typically achieved with the loading and second infusion) in order to provide the metabolic benefits of NAC.

Because the toxicokinetics in these patients may represent a disconnect between the normal toxicokinetics of paracetamol and the pharmacokinetics of NAC, many clinicians in the US have modified NAC therapy along the following principles. All patients have a paracetamol concentration and liver function tests determined at the end of the standard IV NAC regimen. If paracetamol is still present, or signs of significant liver disfunction have developed, IV NAC is continued using the regimen developed by the King's College Liver Institute. With massive ingestions, coingestants such as diphenhydramine, or delayed second peak concentrations of paracetamol, either the rate of the third maintenance infusion is doubled $(12.5 \mathrm{mg} / \mathrm{kg} / \mathrm{hr}$ and continued indefinitely as described above) or the regimen is reinitiated with the original $100 \mathrm{mg} / \mathrm{kg}$ first infusion, and continued using standard parameters and reassessed. The goal is to maintain NAC concentrations at levels that are known to be efficacious when paracetamol concentrations are also significantly elevated.

\section{INTRAVENOUS FAT EMULSION (LIPID RESCUE)}

Among drugs intentionally ingested for attempted suicides, cardiovascular toxins rank highly with regard to both the degree of illness they produce and their casefatality rate. This group of toxins includes many representatives from diverse pharmacologic categories such antihypertensives, anti-arrhythmics, antidepressants, antipsychotics and local anaesthetics. The drugs of concern in these categories share at least two pharmacological properties: they are highly lipid soluble, giving them a large volume of distribution, and their actions occur predominantly on receptors or ion channels located on or near the external lipid bilayer of the cell.Typical clinical features of toxicity include cardiac (hypotension and arrhythmias) and neurologic (altered mental status and seizures) toxicity.

Some therapies have greatly improved the care of poisoned patients, such as hypertonic sodium bicarbonate for cyclic antidepressant and other sodium channel blocker overdoses, ${ }^{67}$ or high-dose insulin euglycaemia therapy for calcium channel blocker toxicity. ${ }^{68}$ Yet in critically ill patients these therapies often fail. In a 1998 paper, Weinberg and colleagues described a fortuitous discovery that $10-30 \%$ intravenous fat emulsion (IFE) protected rats against bupivacaine-induced cardiac arrest. ${ }^{69}$ While bupivacaine toxicity has limited prevalence outside of anaesthesia, this therapy is rapidly becoming acknowledged as a safe and effective treatment for other local anaesthetics (sodium channel blockers) and a wide variety of cardiovascular toxins.

Although the mechanism for what has now been termed 'lipid rescue' has not fully been elucidated, several plausible mechanisms have sound experimental support. The easiest to conceptualise has been called 'lipid sink'. Simply put, if the lipid content of the blood is increased dramatically, the drug will repartition into the blood space, moving away from target organs, and thereby lessening toxicity. This concept of an altered volume of distribution as a result of binding in a 'non-toxic compartment' is analagous to the use of digoxin-specific antibody fragments or multiple-dose activated charcoal. 
TABLE I Lipid rescue therapy

\begin{tabular}{|c|c|}
\hline Indications & Contraindications \\
\hline $\begin{array}{l}\text { Initial response for cardio- } \\
\text { vascular collapse following } \\
\text { an inadvertent intravenous } \\
\text { administration of bupivacaine } \\
\text { or a similar local anaesthetic. } \\
\text { Life-threatening cardiovascular } \\
\text { collapse from a toxin with } \\
\text { high lipid solubility when } \\
\text { standard therapy is failing. }\end{array}$ & $\begin{array}{l}\text { Other than known } \\
\text { hypersensitivity, no absolute } \\
\text { contraindications exist. } \\
\text { Lipid rescue may not } \\
\text { provide additional benefits } \\
\text { if the patient is already } \\
\text { receiving high-dose insulin } \\
\text { euglycaemia therapy. }\end{array}$ \\
\hline Initial bolus ${ }^{71}$ & Maintenance therapy ${ }^{71}$ \\
\hline $1.5 \mathrm{ml} / \mathrm{kg}$ via rapid bolus & $\begin{array}{l}0.25 \mathrm{ml} / \mathrm{kg} / \mathrm{min} \text { for } 30-60 \mathrm{mins} \\
\text { OR } 15 \mathrm{ml} / \mathrm{kg} / \mathrm{hr}\end{array}$ \\
\hline $\begin{array}{l}\text { Bolus dose may be repeated } \\
\text { I-2 times for asystole or } \\
\text { persistent hypertension. }\end{array}$ & $\begin{array}{l}\text { Infusion rate may be increased } \\
\text { for declining blood pressure. }\end{array}$ \\
\hline $\begin{array}{l}\text { Maximal safe dose is } \\
\text { unknown. }\end{array}$ & $\begin{array}{l}\text { Maximal safe dose is } \\
\text { unknown. }\end{array}$ \\
\hline
\end{tabular}

Note: The dosing regimen listed is for $20 \%$ intravenous fat emulsion. These doses should be doubled if a 10\% fat emulsion is used.

Support for this theory comes from the demonstration of enhanced tissue clearance of drugs, ${ }^{70}$ and increased drug concentration in the lipid compartment." The other mechanisms are more complex and extensively reviewed elsewhere. ${ }^{72,73}$ They have been collectively called 'bioenergetic' mechanisms in that lipid serves as an energy substrate for a failing myocardium and directly increases intracellular calcium availability, which is essential for excitation contraction coupling.

Animal experiments provide excellent support for basic science in-vitro and ex-vivo studies. Dramatic examples include the ability of IFE to outperform standard therapy (hypertonic sodium bicarbonate) in a model of cyclic antidepressant toxicity, ${ }^{74}$ and multiple models of successful resuscitation from bupivacaine toxicity (which is almost universally fatal) (1,75 $^{7,}$ and verapamil toxicity. ${ }^{76,77}$ Human data consist of case reports and small case series, some of which chronicle what appears to be dramatic efficacy. ${ }^{78-80}$ Since at present there is no randomised clinical trial, authorities in the field have called for a case registry, which can now be accessed on the internet. ${ }^{81}$

\section{REFERENCES}

I Gunnell D, Eddleston M, Phillips MR et al. The global distribution of fatal pesticide self-poisoning: systematic review. BMC Public Health 2007; 7:357. doi:10.1 I86/I47|-2458-7-357

2 Williams D, Gutiérrez JM, Harrison R et al. The global snake bite initiative: an antidote for snake bite. Lancet 2010; 375:89-91. doi:I0.I0I6/S0|40-6736(09)6II59-4
As with many new therapies several controversies exist. Although many clinicians have adopted a dosing regimen developed for bupivacaine (Table I), it is unclear if this is the optimal regimen. Animal models use wide variations in dose, ${ }^{82}$ and no human dose-finding studies have been performed for obvious ethical reasons. Safety concerns have not been raised with the current human dosing regimen, but the number of patients that have been treated is small and their cases are so complex that adverse effects cannot be excluded. Most importantly, although this therapy is rapidly gaining support in many scenarios, with the exception of bupivacaine toxicity it must be considered somewhat experimental. Thus the greatest controversy is at what point in therapy lipid should be given. At present, the term 'lipid rescue' best describes its role in the therapeutic armamentarium. Under most circumstances existing data are insufficient to support the use of lipid before other standard therapies have been tried. However, since the risk appears low and the benefits are potentially great, it seems reasonable to move toward lipid rescue rapidly when patients are gravely ill and/or response to standard therapy is inadequate.

\section{CONCLUSION}

It is essential for clinicians to recognise that the demographics of life-threatening poisoning are changing. Efforts to reduce fatalities in children have been largely successful and both prevention and treatment must now focus on drug interactions, the elderly, people with low health literacy, substance users and novel treatments for high-risk toxins. The restriction of high-risk toxins and assurance of antidotes and basic resources seem the most cost-effective strategies for the developing world. Although some efforts to remove or restrict high-risk pharmaceuticals have occurred in developed nations, the narrow therapeutic index of many essential pharmaceuticals will pose a continuing problem in depressed and suicidal individuals. New methods of harm reduction and treatment of commonly lethal toxins are being developed. Readers are encouraged to seek out their local toxicologists and poison information and treatment centres for continued updates in these areas.

Disclaimer The findings and conclusions in this article are those of the author and do not necessarily represent the views of the New York City Department of Health and Mental Hygiene. 
5 Walton WW. An evaluation of the Poison Prevention Packaging act. Pediatrics 1982; 69:363-70.

6 Wheatley GM. The Federal Hazardous Substances Labeling Act. Pediatrics 196I; 28:499-500.

7 Sibert JR, Craft AW, Jackson RH. Child-resistant packaging and accidental child poisoning. Lancet 1977; 2:289-90. doi:10.1016/ S0I40-6736(77)90966-7

8 Flanagan RJ, Rooney C, Griffiths C. Fatal poisoning in childhood, England \& Wales 1968-2000. Forensic Sci Int 2005; 148:121-9. doi:10.1016/j.forsciint.2004.04.083

9 Bateman DN. Limiting paracetamol pack size: has it worked in the UK? Clin Toxicol (Phila) 2009; 47:536-4I. doi:I0.1080/I5563650903093I92

10 Hawkins LC, Edwards JN, Dargan PI. Impact of restricting paracetamol pack sizes on paracetamol poisoning in the United Kingdom: a review of the literature. Drug Saf 2007; 30:465-79. doi:10.2165/00002018-200730060-00002

II Fingerhut LA, Cox CS. Poisoning mortality, 1985-1995. Public Health Rep 1998; I 13:218-33.

12 Centers for Disease Control and Prevention (CDC). Increases in age-group-specific injury mortality - United States, 1999-2004. MMWR Morb Mortal Wkly Rep 2007; 56:I28I-4.

13 O'Dowd A. Deaths from drug poisoning in English and Welsh men reach five year peak. BMJ 2008; 337:a I52I.

I4 Bateman DN, Bain M, Gorman D et al. Changes in paracetamol, antidepressants and opioid poisoning in Scotland during the 1990s. QJM 2003; 96:I25-32. doi:10.1093/qjmed/hcg015

15 Manuweera G, Eddleston M, Egodage S et al. Do targeted bans of insecticides to prevent deaths from self-poisoning result in reduced agricultural output? Environ Health Perspect 2008; I 16:492-5.

16 Dole VP, Nyswander M.A medical treatment for diacetylmorphine (heroin) addiction. A clinical trial with methadone hydrochloride. JAMA 1965; 193:646-50.

17 Cook CC. Syringe exchange. Lancet 1987; 1:920-I. doi:10.1016/ SOI40-6736(87)92894-7

18 Raymond CA. First needle-exchange program approved; other cities await results. JAMA 1988; 259:1289-90. doi:10.100I/ jama.259.9.1289

19 Bryant WK, Galea S, Tracy M et al. Overdose deaths attributed to methadone and heroin in New York City, 1990-1998. Addiction 2004; 99:846-54. doi:I0.I I I I/j.I360-0443.2004.00693.x

20 Bernstein KT, Bucciarelli A, Piper TM et al. Cocaine- and opiaterelated fatal overdose in New York City, 1990-2000. BMC Public Health 2007; 7:31. doi:I0.II86/|47|-2458-7-31

2I Chan GM, Stajic M, Marker EK et al. Testing positive for methadone and either a tricyclic antidepressant or a benzodiazepine is associated with an accidental overdose death: analysis of medical examiner data. Acad Emerg Med 2006; 13:543-7. doi:I0.IIII/j.I553-27I2.2006. tb0I006.x

22 Davidson PJ, McLean RL, Kral AH et al. Fatal heroin-related overdose in San Francisco, 1997-2000: a case for targeted intervention. J Urban Health 2003; 80:26I-73. doi:10.1093/jurban/jtg029

23 Schumann H, Erickson T, Thompson TM et al. Fentanyl epidemic in Chicago, Illinois and surrounding Cook County. Clin Toxicol (Phila) 2008; 46:50I-6. doi:10.1080/I5563650701877374

24 Fischer B, Rehm J. Deaths related to the use of prescription opioids. CMAJ 2009; I8I:88I-2. doi:I0.1503/cmaj.09|79|

25 Baca CT, Grant KJ. Take-home naloxone to reduce heroin death Addiction 2005; I00: I823-3I. doi:I0. I I II/j.I360-0443.2005.0I259.x

26 Goldstein A, Herrera J. Heroin addicts and methadone treatment in Albuquerque: a 22-year follow-up. Drug Alcohol Depend 1995; 40: I39-50. doi: I0.1016/0376-87|6(95)01205-2

27 Hickman M, Carnwath Z, Madden P et al. Drug-related mortality and fatal overdose risk: pilot cohort study of heroin users recruited from specialist drug treatment sites in London. J Urban Health 2003; 80:274-87. doi: 10.1093/jurban/jtg030

28 Sporer KA. Acute heroin overdose. Ann Intern Med 1999; 130:584-90.

29 McGregor C, Darke S, Ali R et al. Experience of non-fatal overdose among heroin users in Adelaide, Australia: circumstances and risk perceptions. Addiction 1998; 93:70I-II.doi: I0.1046/ i.1360-0443.1998.9357016.x
30 Powis B, Strang J, Griffiths P et al. Self-reported overdose among injecting drug users in London: extent and nature of the problem. Addiction 1999; 94:47I-8. doi: 10.1046/j. I360-0443.1999.94447/2.x

3I Strang J, Darke S, Hall W et al. Heroin overdose: the case for takehome naloxone. BMJ 1996; 312:1435-6.

32 Darke S, Ross J, Hall W. Overdose among heroin users in Sydney, Australia: II. Responses to overdose. Addiction 1996; 91:413-7. doi:I0.1 I I I/j.I360-0443.1996.tb02290.x

33 Hoffman RS, Goldfrank LR. The poisoned patient with altered consciousness. Controversies in the use of a 'coma cocktail'.JAMA 1995; 274:562-9. doi:10.1001/jama.274.7.562

34 Kelly AM, Kerr D, Dietze $P$ et al. Randomised trial of intranasal versus intramuscular naloxone in prehospital treatment for suspected opioid overdose. Med J Aust 2005; 182:24-7.

35 Beletsky L, Ruthazer R, Macalino GE et al. Physicians' knowledge of and willingness to prescribe naloxone to reverse accidental opiate overdose: challenges and opportunities. J Urban Health 2007; 84:|26-36. doi:|0.|007/s|| 524-006-9|20-z

36 Lopez Gaston R, Best D, Manning V et al. Can we prevent drug related deaths by training opioid users to recognise and manage overdoses? Harm Reduct J 2009; 6:26. doi: I0.I I86/I477-75I 7-6-26

37 Strang J, Manning V, Mayet S et al. Overdose training and take-home naloxone for opiate users: prospective cohort study of impact on knowledge and attitudes and subsequent management of overdoses. Addiction 2008; 103: I648-57. doi: I0.I I I I/j. I360-0443.2008.023 I4.x

38 Green TC, Heimer R, Grau LE. Distinguishing signs of opioid overdose and indication for naloxone: an evaluation of six overdose training and naloxone distribution programs in the United States. Addiction 2008; 103:979-89. doi:I0.I I I I/j.1360-0443.2008.02I82.x

39 Seal $\mathrm{KH}$, Thawley R, Gee L et al. Naloxone distribution and cardiopulmonary resuscitation training for injection drug users to prevent heroin overdose death: a pilot intervention study.J Urban Health 2005; 82:303-II. doi:10.1093/jurban/jti053

40 Galea S, Worthington N, Piper TM et al. Provision of naloxone to injection drug users as an overdose prevention strategy: early evidence from a pilot study in New York City. Addict Behav 2006; 31:907-12. doi:10.1016/j.addbeh.2005.07.020

4I Doe-Simkins M, Walley AY, Epstein A et al. Saved by the nose: bystander-administered intranasal naloxone hydrochloride for opioid overdose. Am J Public Health 2009; 99:788-9I. doi:I0.2105/ AJPH.2008.I46647

42 Kim D, Irwin KS, Khoshnood K. Expanded access to naloxone: options for critical response to the epidemic of opioid overdose mortality. Am J Public Health 2009; 99:402-7. doi: I0.2 I05/AJPH.2008.I36937

43 Macdonald H. Cocaine use in England and Wales rises as cannabis use falls. BMJ 2008; 337:a I367. doi:I0.II36/bmj.al367

44 Pavarin RM. Cocaine consumption and death risk: a follow-up study on 347 cocaine addicts in the metropolitan area of Bologna. Ann Ist Super Sanita 2008; 44:9I-8.

45 United Nations Office on Drugs and Crime. World drug report 2009. New York: United Nations; 2009.

46 Goldfrank LR, Hoffman RS. The cardiovascular effects of cocaine. Ann Emerg Med 1991; 20:165-75. doi:I0.1016/S0196-0644(05)8I2I7-X

47 Stewart DJ, Inaba T, Tang BK et al. Hydrolysis of cocaine in human plasma by cholinesterase. Life Sci 1977; 20: 1557-63. doi: 10.1016/00243205(77)90448-9

48 Hoffman RS, Henry GC, Howland MA et al. Association between lifethreatening cocaine toxicity and plasma cholinesterase activity. Ann Emerg Med 1992; 21:247-53. doi:10.1016/S0196-0644(05)80883-2

49 Hoffman RS, Henry GC, Wax PM et al. Decreased plasma cholinesterase activity enhances cocaine lethality in mice. J Pharmacol Exp Ther 1992; 263:698-702.

50 Hoffman RS, Morasco R, Goldfrank LR. Administration of purified human plasma cholinesterase protects against cocaine toxicity in mice. JToxicol Clin Toxicol 1996; 34:259-66. doi:I0.3109/155636596090I3786

5 I Wood SK, Narasimhan D, Cooper Z et al. Prevention and reversal by cocaine esterase of cocaine-induced cardiovascular effects in rats. Drug Alcohol Depend 2010; 106:219-29. doi:10.1016/j. drugalcdep.2009.09.00I 
52 Martell BA, Orson FM, Poling J et al. Cocaine vaccine for the treatment of cocaine dependence in methadone-maintained patients: a randomized, double-blind, placebo-controlled efficacy trial. Arch Gen Psychiatry 2009; 66:1116-23. doi:10.1001/ archgenpsychiatry.2009.128

53 Ostapowicz G, Fontana RJ, Schiødt FV et al; U.S. Acute Liver Failure Study Group. Results of a prospective study of acute liver failure at 17 tertiary care centers in the United States. Ann Intern Med 2002; I37:947-54.

54 Chun LJ,Tong MJ, Busuttil RW et al.Acetaminophen hepatotoxicity and acute liver failure. J Clin Gastroenterol 2009; 43:342-9. doi:I0.1097/MCG.0b013e31818a3854

55 Prescott LF, Roscoe P,Wright $\mathrm{N}$ et al. Plasma-paracetamol half-life and hepatic necrosis in patients with paracetamol overdosage. Lancet 197I; I:5I9-22. doi:I0.1016/S0|40-6736(7I)9|I25-I

56 Rumack $\mathrm{BH}$, Matthew $\mathrm{H}$. Acetaminophen poisoning and toxicity. Pediatrics 1975; 55:87I-6.

57 Renzi FP, Donovan JW, Martin TG et al. Concomitant use of activated charcoal and $\mathrm{N}$-acetylcysteine. Ann Emerg Med 1985 14:568-72. doi:I0.1016/S0196-0644(85)8078|-2

58 Ekins BR, Ford DC, Thompson Ml et al. The effect of activated charcoal on $\mathrm{N}$-acetylcysteine absorption in normal subjects. Am J Emerg Med 1987; 5:483-7. doi:10.1016/0735-6757(87)90166-5

59 Spiller HA, Sawyer TS. Impact of activated charcoal after acute acetaminophen overdoses treated with $\mathrm{N}$-acetylcysteine. J Emerg Med 2007; 33:|4|-4. doi:10.1016/j.jemermed.2007.02.016

60 Spiller HA, Winter ML, Klein-Schwartz W et al. Efficacy of activated charcoal administered more than four hours after acetaminophen overdose.J Emerg Med 2006; 30:I-5. doi:I0.1016/j. jemermed.2005.02.019

6I Smilkstein MJ, Knapp GL, Kulig KW et al. Efficacy of oral $\mathrm{N}$-acetylcysteine in the treatment of acetaminophen overdose. Analysis of the national multicenter study (1976 to 1985). N Engl J Med 1988; 319:1557-62.

62 Doyon S, Klein-Schwartz W. Hepatotoxicity despite early administration of intravenous $\mathrm{N}$-acetylcysteine for acute acetaminophen overdose. Acad Emerg Med 2009; 16:34-9. doi:I0.1 I I I/j. I553-27I2.2008.00296.x

63 Smith SW, Howland MA, Hoffman RS et al. Acetaminophen overdose with altered acetaminophen pharmacokinetics and hepatotoxicity associated with premature cessation of intravenous $\mathrm{N}$-acetylcysteine therapy. Ann Pharmacother 2008; 42:1333-9. doi: I0.1345/aph. IK680

64 Schwartz EA, Hayes BD, Sarmiento KF. Development of hepatic failure despite use of intravenous acetylcysteine after a massive ingestion of acetaminophen and diphenhydramine. Ann Emerg Med 2009; 54:42I-3. doi:10.1016/j.annemergmed.2008.10.001

65 Keays R, Harrison PM, Wendon JA et al. Intravenous acetylcysteine in paracetamol induced fulminant hepatic failure: a prospective controlled trial. BMJ 1991; 303:1026-9. doi:I0.I I36/bmj.303.6809.1026

66 Prescott LF, Donovan JW, Jarvie DR et al. The disposition and kinetics of intravenous $\mathrm{N}$-acetylcysteine in patients with paracetamol overdosage. Eur J Clin Pharmacol 1989; 37:50I-6. doi:I0.1007/BF00558I3I

67 Bradberry SM, Thanacoody HK, Watt BE et al. Management of the cardiovascular complications of tricyclic antidepressant poisoning: role of sodium bicarbonate. Toxicol Rev 2005; 24:195-204. doi:I0.2 I65/00I39709-200524030-00012
68 Greene SL, Gawarammana I, Wood DM et al. Relative safety of hyperinsulinaemia/euglycaemia therapy in the management of calcium channel blocker overdose: a prospective observational study. Intensive Care Med 2007; 33:20I9-24. doi:I0.1007/s00I34007-0768-y

69 Weinberg GL, VadeBoncouer T, Ramaraju GA et al. Pretreatment or resuscitation with a lipid infusion shifts the dose-response to bupivacaine-induced asystole in rats. Anesthesiology 1998; 88: 10715. doi:10.1097/00000542-199804000-00028

70 Weinberg GL, Ripper R, Murphy P et al. Lipid infusion accelerates removal of bupivacaine and recovery from bupivacaine toxicity in the isolated rat heart. Reg Anesth Pain Med 2006; 31:296-303.

7I Harvey M, Cave G, Hoggett K. Correlation of plasma and peritoneal diasylate clomipramine concentration with hemodynamic recovery after intralipid infusion in rabbits. Acad Emerg Med 2009; 16: I 5 I-6. doi: I0. I I I I/j. I553-27 |2.2008.003 I3.x

72 Weinberg G. Lipid rescue resuscitation from local anaesthetic cardiac toxicity. Toxicol Rev 2006; 25: I 39-45. doi: I 0.2 I65/00 I39709. 200625030-0000I

73 Cave G, Harvey M. Intravenous lipid emulsion as antidote beyond local anesthetic toxicity: a systematic review. Acad Emerg Med 2009; 16:8I5-24. doi:I0. II I I/j. I553-27I2.2009.00499.x

74 Harvey M, Cave G. Intralipid outperforms sodium bicarbonate in a rabbit model of clomipramine toxicity. Ann Emerg Med 2007; 49:178-85. doi:10.1016/j.annemergmed.2006.07.016

75 Weinberg G, Ripper R, Feinstein DL et al. Lipid emulsion infusion rescues dogs from bupivacaine-induced cardiac toxicity. Reg Anesth Pain Med 2003; 28:198-202.

76 Bania TC, Chu J, Perez E et al. Hemodynamic effects of intravenous fat emulsion in an animal model of severe verapamil toxicity resuscitated with atropine, calcium, and saline. Acad Emerg Med 2007; |4: 105-II. doi:I0.IIII/j.1553-27| 2.2007.tb0|752.x

77 Tebbutt S, Harvey M, Nicholson T et al. Intralipid prolongs survival in a rat model of verapamil toxicity. Acad Emerg Med 2006; I 3:I349. doi:I0.IIII/j.I553-27|2.2006.tb0 I66I.x

78 Sirianni AJ, Osterhoudt KC, Calello DP et al. Use of lipid emulsion in the resuscitation of a patient with prolonged cardiovascular collapse after overdose of bupropion and lamotrigine. Ann Emerg Med 2008; 51:4I2-5. doi: 10.1016/j.annemergmed.2007.06.004

79 Litz RJ, Popp M, Stehr SN et al. Successful resuscitation of a patient with ropivacaine-induced asystole after axillary plexus block using lipid infusion. Anaesthesia 2006; 61:800-I. doi: I0. I I I I/ j. I365-2044.2006.04740.x

80 Young AC, Velez LI, Kleinschmidt KC. Intravenous fat emulsion therapy for intentional sustained-release verapamil overdose. Resuscitation 2009; 80:591-3. doi:10.1016/j.resuscitation.2009.0I.023

8I Harvey M, Cave G. Lipid registry: intravenous lipid emulsion as antidote. Emerg Med Australas 2009; 21;521-2. doi:I0.I I I I/j. I742-6723.2009.0I237.x

82 Perez E, Bania TC, Medlej K et al. Determining the optimal dose of intravenous fat emulsion for the treatment of severe verapamil toxicity in a rodent model. Acad Emerg Med 2008; I5:1284-9. doi:I0.I I I I/j. I553-27| 2.2008.00259.x 